\title{
Wireless Sensor Network Based Monitoring Sensory System towards Environmental Pollution
}

\author{
Oky Dwi Nurhayati ${ }^{1}$, Sumardi $^{2}$ and Eko Didik W ${ }^{1}$ \\ ${ }^{1}$ Computer Engineering, \\ ${ }^{2}$ Electrical Engineering \\ Engineering Department, Diponegoro University \\ okydwin@gmail.com; sumardi.undip@gmail.com;didik@live.undip.ac.id
}

\begin{abstract}
Air pollution is an issue that is being concerned by public - particularly in campus environment. This has led the stakeholders in campus to take apart in monitoring the environment condition by carrying out a number of researches on green campus by monitoring the environment condition around campus. The advance of science and technology and planted system principally can cope with the issue by making an application system equipped with a wireless Sensor to monitor the level of air quality. This system supports a number of environment monitoring Sensors integrated in a wireless Sensor network. This research aims to design a Sensory system that is able to monitor the environment quality in the wireless Sensor network in the area of UNDIP (Diponegoro University). The built system uses a number of environment monitoring Sensors interconnected in a wireless Sensor network. The technology-based environment monitor can assist the environmentalists to monitor the campus area. The tool of environment monitor can be in the form of the detecting Sensor of the concentration of $\mathrm{CO}, \mathrm{NO}_{2}$, and density of dust particles, temperature, air humidity, and light intensity to make the Sensor data identifiable by all environmentalists in everywhere. For this, it requires a media that is able to present the real-time Sensor data. The Sensors used to read the parameters of environment include TGS 2600 Sensor to read the concentration of the carbon monoxide (CO), TGS 2201 Sensor for the nitrogen dioxide $\left(\mathrm{NO}_{2}\right)$, GP2Y1010AUOF Sensor for the density of dust particles, BH1750 Sensor for the light intensity, and SHT11 Sensor to read the humidity and temperature of the environment. These Sensor systems use the microcontroller ATmega 2560-based Arduino board as the central of system controller. This system is also equipped with RTC as the timer and GPS as the coordinate of the location where the Sensor system in the non-cable Sensor network is located as a node. The result of this research is the design of Sensor system that is able to read a number of parameters as the control of the air quality of environment around the UNDIP campus well.
\end{abstract}

Keywords: Air pollution, non-cable Sensor, microcontroller, design Sensor system for the environment quality

\section{Introduction}

The composition of the clean air from one place to other place is quite varied. The number of the motorists is always increasing in each year, thus enabling to increase the volume of the traffic in each road.

Most of industrial machines and motor vehicles use gasoline and diesel fuel. There is no any combustion process in a motor vehicle going perfectly. This then will produce hydrocarbon $(\mathrm{HC})$, carbon monoxide $(\mathrm{CO})$, nitrogen dioxide $\left(\mathrm{NO}_{2}\right)$, hydrogen $(\mathrm{H})$, sulfur oxides $\left(\mathrm{SO}_{2}\right)$ and lead $(\mathrm{Pb})$. These gases are the harmful substances that cause air 
pollution, a condition when the air around or near the home contains the contaminants at harmful level for human or environment [1].

Recently, air pollution comes to be an issue that is mostly concerned by publicparticularly for the campus environment. This then encourages the stakeholders in campus to take a part in monitoring the condition of the environment in campus by carrying out a number of researches themed as Green Campus.

In this research, the monitoring was conducted towards the condition of environment around the campus with some parameters that are observed such as concentration of carbon monoxide $(\mathrm{CO})$, nitrogen dioxide $\left(\mathrm{NO}_{2}\right)$, density of the dust particles, light intensity, air density and the environment temperature.

This research was conducted to make a system equipped with a Sensor to monitor the level of air quality using wireless. This system supports a number of Sensory systems to monitor the environment by placing it in a number of strategic spots in campus area. By using the wireless communication, the installation will be much easier. This research also has an aim to make a Sensor system that can provide the environment data (concentration of $\mathrm{CO}$ and $\mathrm{NO}_{2}$, the density of dust particles, temperature, air humidity and light intensity) from many spots accurately, real-time, reliable and energy efficient and able to be the platform in presenting the environment data for the supporting system of decision for the campus development and in providing information about environment for the civitas of academicians concerned with environment.

\section{Theory}

A number of researches have been carried out on the information system of environment that explains the impact of the environment on public health and the way to manage its impact. One of the addressed issues is to deal with the threat towards the air quality as the result of human and natural activities such as industry, transportation, fire, or volcano eruption through the development of information system of environment. ${ }^{[24]} \mathrm{A}$ number of policies need to be issued; one of which is by making a monitoring system on the air quality using remote sensing [25].

At the moment, the development of the monitoring system on the air quality at distance has been supported by the relevant technology, including 1) Sensor that is more affordable, portable and able to provide the data at real time with high resolution, 2) the higher capability of computation and visualization of processor (microprocessor) and 3 ) the more developed infrastructure of wireless communication [26]. Such technology can accelerate the development of the technology of wireless Sensor network (WSN). The data of a variety of heterogenic Sensors can be acquired and processed by means of microprocessor / microcontroller through the various wireless network such as ZigBee, GSM and Wi-Fi [27]. On the other side, the air pollution has brought an impact on health. [28] The parameter of contaminant that needs to be well concerned is the nature of the materials of contaminants, sources and distribution, the impacts that might occur and the way of controlling. The type of the parameter of the air pollutants include sulfur dioxide $\left(\mathrm{SO}_{2}\right)$, carbon monoxide $(\mathrm{CO})$, nitrogen dioxide $\left(\mathrm{NO}_{2}\right)$, oxidant $\left(\mathrm{O}_{3}\right)$, hydro carbon $(\mathrm{HC})$, PM 10, PM 2,5, TSP (dust), Pb (Lead) and dust fall [25].

The Sensor that can be detected the contaminant parameter depics in Table 1. 
Table 1. Sensor and Parameter that can be Detected and Its Function

\begin{tabular}{|l|l|l|l|}
\hline No & $\begin{array}{l}\text { Environmental } \\
\text { Parameter }\end{array}$ & Sensor & Function \\
\hline 1 & $\mathrm{CO}$ & TGS2442 & Gasoline vehicle contamination \\
\hline 2 & $\mathrm{NO}_{2}$ & TGS2201 & Diesel fuel vehicle contamination \\
\hline 3 & $\mathrm{HC}$ & MQ-4 & Diesel fuel vehicle contamination \\
\hline 4 & $\mathrm{PM}$ & GP2Y1010AU0F & Density of dust particle \\
\hline 5 & Aqueous vapor & TGS2180 & Data analysis on aqueous vapor \\
\hline 6 & Temperature & LM35 & Data analysis on temperature \\
\hline 7 & Light intensity & Photodiode & Data analysis on light intensity \\
\hline
\end{tabular}

In UNDIP campus, the mitigation of the climate change is becoming a main environmental issue faced by the campus stakeholders including its correlation with the campus endurance/sustainability. A number of efforts have been given to reduce the emission of carbon, manage and improve the sustainable campus development [3-5].

The scheme of the sustainable campus development involves 3 aspects of indicator: environment, (research) economy, and (society) education [6]. Those three aspects become the pillars that are connected to each other and multidimensional to create an excellent campus that is environmentally sound including the efficient use and the management of energy, environmentally sound research and the concern of campus civitas towards output and outcome [7-8].

The metrics of Environmental and Social Responsibility (ESR), UI GreenMetric and Princeton Review can be used to evaluate the strategy/policy and endeavor of campus in realizing the green campus [3, 9-11]. The indicators assessed include the management of campus environment and infrastructure regarding the use of electricity, number of cars/motorcycles, the use of energy saving devices, policy on the use of renewable energy, policy on the reduction of gas emission and policy on the transportation to limit the number of vehicles in campus.

The research on the implementation of the Xbee-based wireless Sensor network with the case study of temperature and humidity monitoring is designed to build and implement a wireless Sensory network system to measure, send and collect the data in the form of information about the value of temperature and humidity using 2 Sensory nodes and 1 sink. Each node consists of Sensor, RTC, and microcontroller of AVR series ATmega328. Module of Xbee ZB was used as a sender and receiver for the data [30].

Other research on the design of wireless Sensor design to monitor the temperature and humidity used nRF24L01+ purposely to build a device to monitor the temperature and humidity in some of spots using the wireless Sensor network by displaying the data of the webpage. This system consisted of 2 Sensor nodes and one node of concentrator. Sensor node functioned to read the temperature and humidity surrounding and send the data as a result of reading the Sensor to the node of concentrator. Meanwhile, the node of concentrator functioned to collect the data from the Sensor node to be then displayed on the webpage. Here, DHT11 was used as the Sensor of the temperature and humidity [31].

The wireless Sensor network is an integrated system consisting of a group of nodes/module of Sensors distributed and connected using wireless in a topology of network and functions to extract and share information to be processed in accordance with its application field. The Sensor node as the network developer consists of main parts: Sensor to detect and measure the applicative parameters, processor to process the data to be information, communication as the media data sending, and capacity management to guarantee all systems to run optimally [3]. Figure 1 describes the wireless Sensor network. 


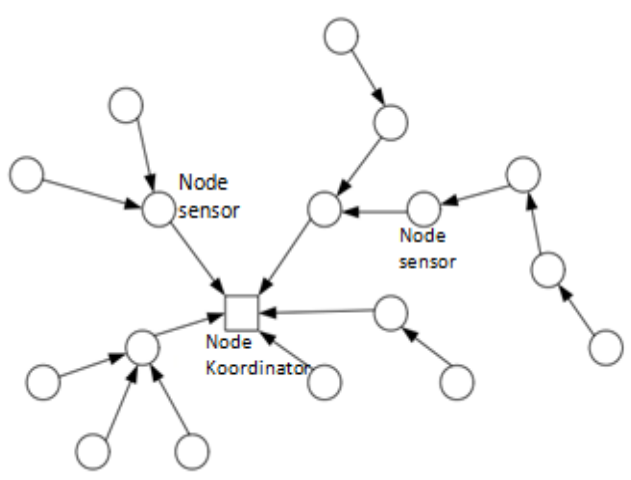

Figure 1. Structure of Wireless Sensor Network

All information is sent to the coordinator node from one Sensor node directly through other nodes as the repetition in a network. Sensor node is the most important part in a wireless Sensor network since the information of Sensor data is collected, converted into digital information and then processed and sent as a data that has been processed [5].

In this research, a number of hardware were used including: Arduino Mega 2560, ATmega2560-based microcontroller board with 54 digital pins of input/output with 14 pins that could be used as the output of PWM, 16 pins as the analogue input and 4 pins as the port of serial UART. Arduino Mega 2560 is the latest version as a replacement of ATmega128 microcontroller-based Arduino Mega [6]. Sensor functioned to obtain a system input coming from the natural physical phenomena, such as temperature, humidity, light intensity, concentration of gas and others. Sensor then changed the physical quantities into the electrical quantities that was used as the information [4].

In this research, a number of types such as TGS 2201 functioned to measure the level of nitrogen dioxide $\left(\mathrm{NO}_{2}\right)$, TGS 2600 as the Sensor of carbon monoxide (CO), GP2Y1010AU0F as the dust optic Sensor, BH1750 as the light intensity Sensor and SHT11 as the Sensor of humidity and environmental temperature were used.

\section{Method}

A number of devices required include:

1. System using the ATmega 2560 microcontroller on the Arduino board as the controller central to read the value of the Sensor output.

2. System was run with the capacity quantum of $9 \mathrm{~V}$.

3. System in the form of printed circuit designed to be installed with Arduino Mega 2560 board.

4. System using the programming language $\mathrm{C}$ applied in the software of the Arduino IDE software.

This research ran the designing process of both in the form of hardware and in the form of software to build the system. The hardware consisted of the main hardware required by the system to the supporting electronic instruments. Figure 2 displays block diagram showing a design of hardware system. 


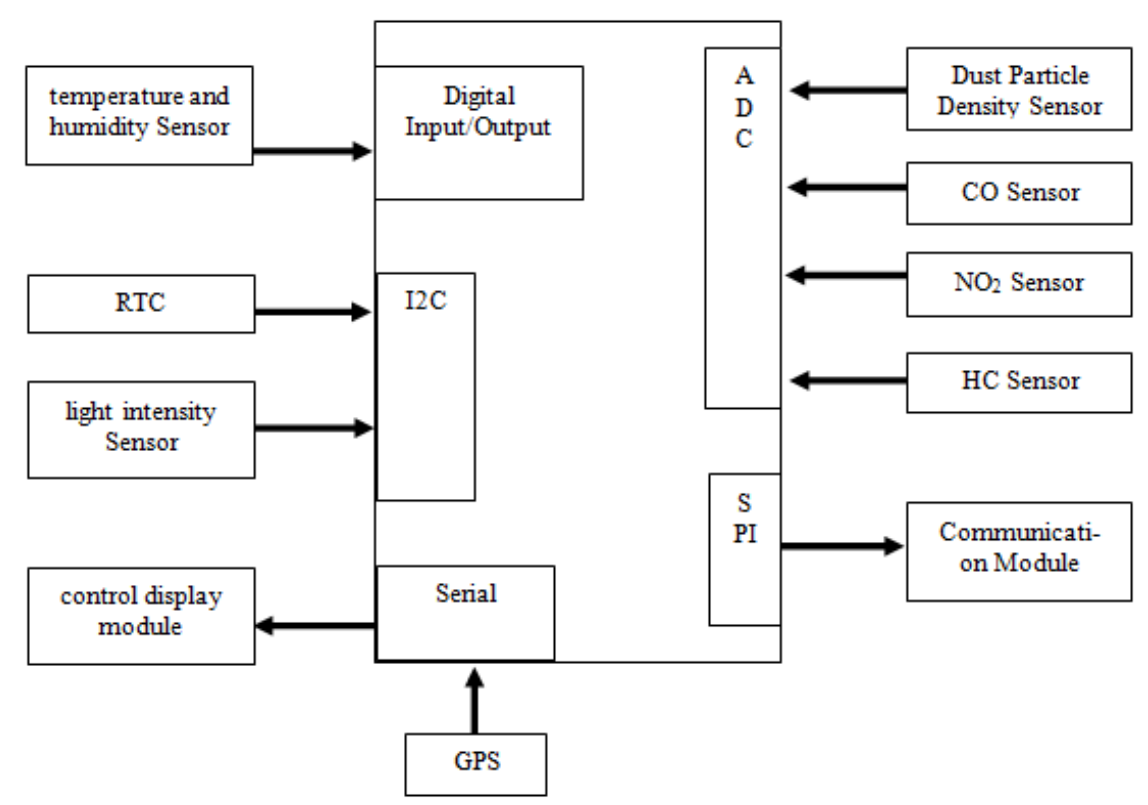

Figure 2. Block Diagram of Hardware System

The center of system controller used the ATmega 2560 microcontroller on the Arduino Mega 2560 board. The components correlated to the system include GP2Y1010AU0F as the Sensor of Dust Particle Density, TGS 2600 as the Sensor of CO, TGS 2201 as the Sensor of $\mathrm{NO}_{2}$ and $\mathrm{HC}$, SHT11 as the Sensor of temperature and humidity, BH1750 as the Sensor of light intensity, module of DS1307 as RTC (Real Time Clock), and the receiver of GPS GY-GPS6MV2 as the receiver of GPS coordinates. Meanwhile, for the module of control of display, this research used Arduino Uno as the controller of displaying the dot of matrix p10 and for the module of communication; it used the module of the nRF905radio.

Microcontroller in this system used ATmega 2560 with the Arduino Mega 2560 board that functions to process the input data from the Sensor, RTC and GPS.

The design of the software explains the phases in building system in the form of the program controlling the hardware. The system was able to read the condition of the environment from the Sensor output, time in accordance with the installed RTC, and coordination of the system location in line with GPS receiver, and to schedule the Sensor reading, data delivery and to display the data in the matrix dot displayer. Figure 3 displays the flow chart for the general program design. 


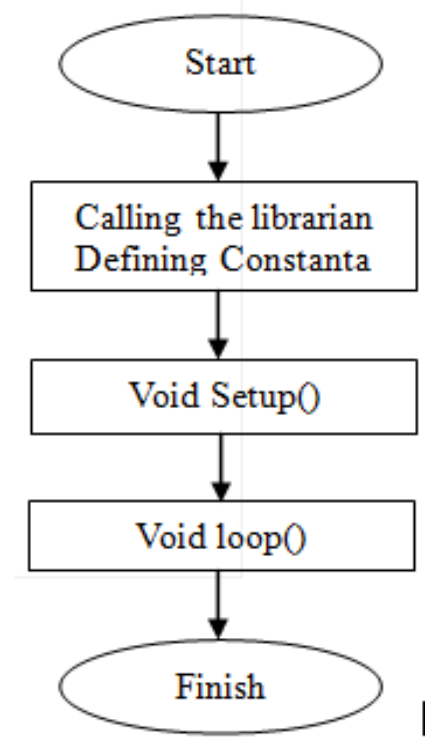

Figure 3. Flowchart of the Software Design

Figure 3 explains the book call required in the program that is the communication book of $I^{2}$ C, RTC, GPS, Sensor of light intensity, and Sensor of temperature and humidity. The next one is the void setup process (). This process contains all commands and initialization executed once only. The last process is the void loop process (), containing the command that would be executed for several times.

\section{Results of the Research}

The electronic circuit board design was made using the Eagle 7.3.0 Professional software. It was $106.68 \mathrm{~mm}$ for length and $67.31 \mathrm{~mm}$ for width. Meanwhile, the width of each of its line was $0.61 \mathrm{~mm}$. This electronic circuit board used a single layer. This design was then printed on the electronic circuit board and installed with the system components in line with the system design. Figure 4 shows the circuit board directly connected to the existing pins on the board of Arduino Mega 2560.

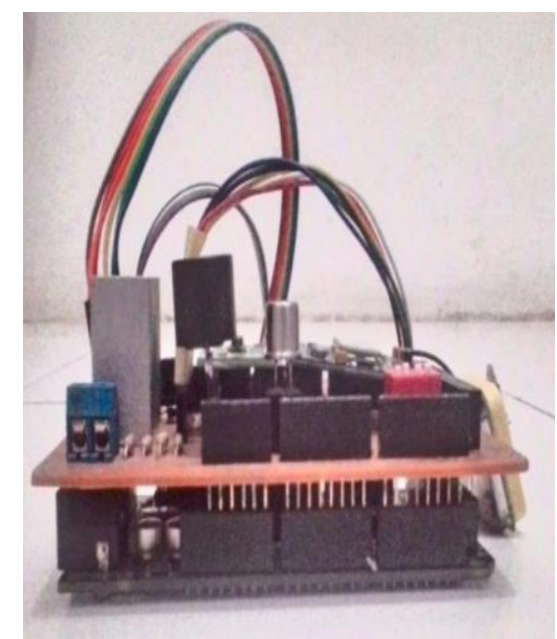

Figure 4. The Electronic Circuit Board of System

Figure 5 shows the graph of the comparison in the value of the datasheet and the values measured in the system Sensor of the design result. 


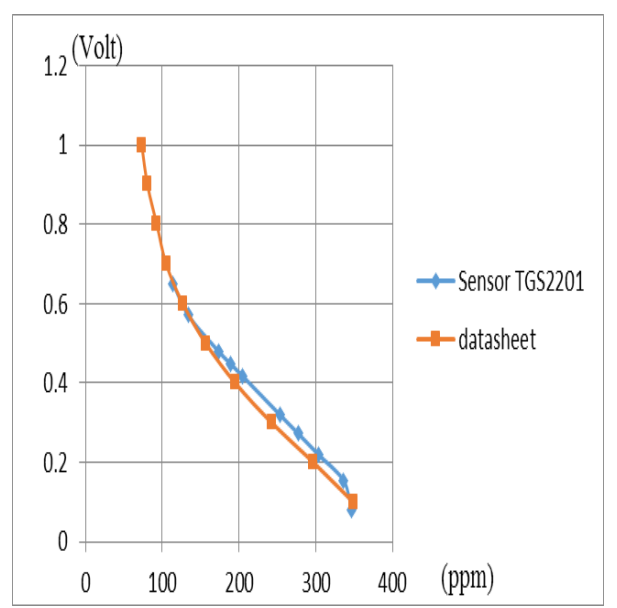

Figure 5. The Comparison Test Result of TGS 2201 Sensor and Datasheet

As shown in Figure 5, the result of the testing that could be measured by Sensor was less than $0.7 \mathrm{ppm}$, while, on the datasheet, the data that could be measured reached at 1 ppm. This was due to the condition when the test was performed, and the existing concentration of NO that was read did not reach $1 \mathrm{ppm}$.

The further test was the test on the Sensor of TGS 2600 for the parameter of concentration of $\mathrm{CO}$. This testing was performed by comparing the value of the output of the Sensor using a measurer in the form of $\mathrm{CO}$ meter from Extech Instrument. The testing was performed at 15 times using the smoke as the $\mathrm{CO}$ pollutant. Table 2 displays the results of the reading $\mathrm{CO}$ read by the Sensor and measurer.

Table 2. The Test Result of TGS 2600 Sensor

\begin{tabular}{|c|c|c|c|}
\hline No. & TGS 2600 (ppm) & CO Meter (ppm) & Difference \\
\hline 1 & 0.00 & 0 & 0.00 \\
\hline 2 & 1.82 & 1 & 0.82 \\
\hline 3 & 2.69 & 2 & 0.69 \\
\hline 4 & 3.57 & 3 & 0.57 \\
\hline 5 & 4.57 & 4 & 0.57 \\
\hline 6 & 5.44 & 5 & 0.44 \\
\hline 7 & 6.32 & 6 & 0.32 \\
\hline 8 & 7.32 & 7 & 0.32 \\
\hline 9 & 8.19 & 8 & 0.19 \\
\hline 10 & 9.07 & 9 & 0.07 \\
\hline 11 & 10.07 & 10 & 0.07 \\
\hline 12 & 11.92 & 11 & 0.92 \\
\hline 13 & 19.82 & 18 & 1.82 \\
\hline 14 & 20.90 & 20 & 0.90 \\
\hline 15 & 32.74 & 30 & 2.74 \\
\hline \multicolumn{3}{|c|}{ Average } & 0.6952 \\
\hline
\end{tabular}

It can be shown in Table 2, it can be explained that the means of differences value $\mathrm{CO}$ from the Sensors and CO meter was at 0.69 . Thus, the reading of CO concentration in the 
system functioned well. Figure 6 describes the graph of the data comparison read by Sensor using the measurers.

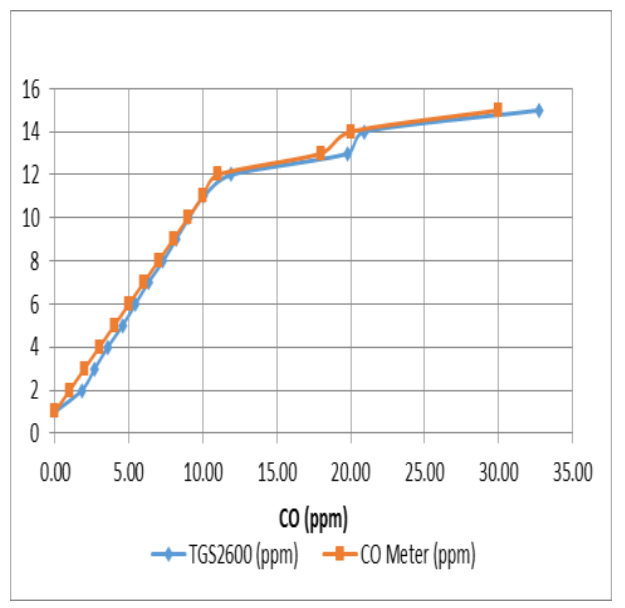

Figure 6. The Comparison Test Result of TGS 2600 Sensor and CO meter

The Sensor of GP2Y1010AU0F is a Sensor used to measure the density of the dust particles in the air. This Sensor is able to measure the dust particles from $0 \mu \mathrm{g} / \mathrm{m}^{3}$ to less than $1000 \mu \mathrm{g} / \mathrm{m}^{3}$. The test of this Sensor was performed by measuring the value of the voltage and the dust particle on the Sensor before being compared to the datasheet Sensor. Based on the datasheet from the Sensor of GP2Y1010AU0F, it is found the characteristics of the Sensors in line with the voltage value of the output and the dust particles that can be measured. The test was performed at 15 times of Sensor reading. For each reading, the smoke with different concentration was used as the dust particle sources.

Figure 7 depics the graph of data comparison read by the Sensor using the measurer based upon the result of the test.

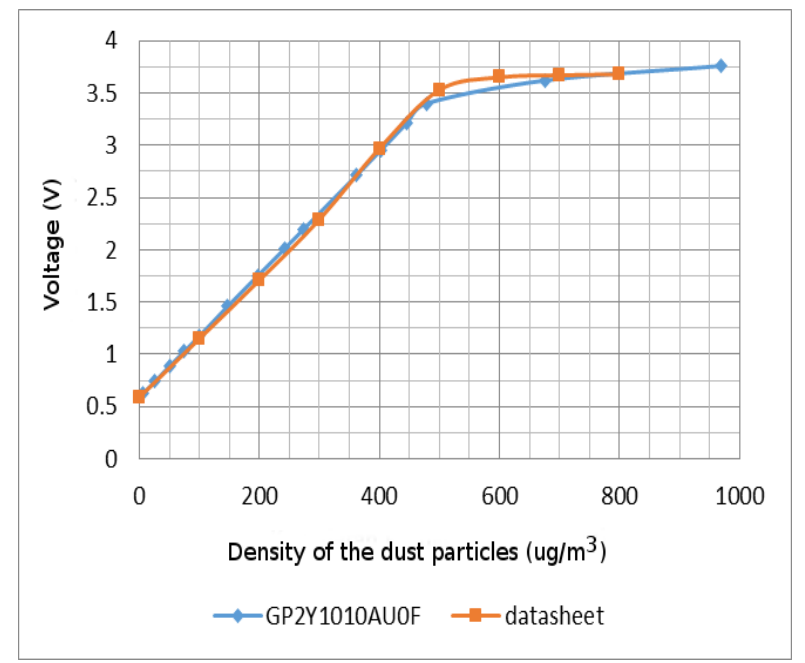

\section{Figure 7. The Comparison Test Result of P2Y1010AU0F Sensor and Datasheet}

Based upon Figure 7, Sensor has a better measurement from $0 \mu \mathrm{g} / \mathrm{m}^{3}$ to $500 \mu \mathrm{g} / \mathrm{m}^{3}$. For the measurement above $500 \mu \mathrm{g} / \mathrm{m}^{3}$, the Sensor measurement would be adverse. This is in line with the characteristics of the Sensor on the datasheet in which the increase of the voltage value resulted from the Sensor would be highly influential towards the increase of the measured dust particles. 
The further test was performed on the Sensor of light intensity. The test was performed by comparing the output value of the Sensor with the light meter in the measurer of multifunction of Krisbow KW06-291. This tool has a range of reading from 0 to 20000 lux.

From the result of test, it is found accuracy based upon the comparison of the value of the Sensor reading with the measurer at 0.10 times from the reading of the Sensors. The difference of this reading is in line with the Sensor data sheet that has the accuracy ranging from 0.96 to 1.44 times. From the data, it can be found that the level of the errors in reading Sensor was 2.8lux. Such reading error could be higher if the reading Sensor towards light intensity was higher than the values that have been obtained in the test. Figure 8 depics the graph of the data comparison measured by the Sensors with the comparing measurer based upon the test result.

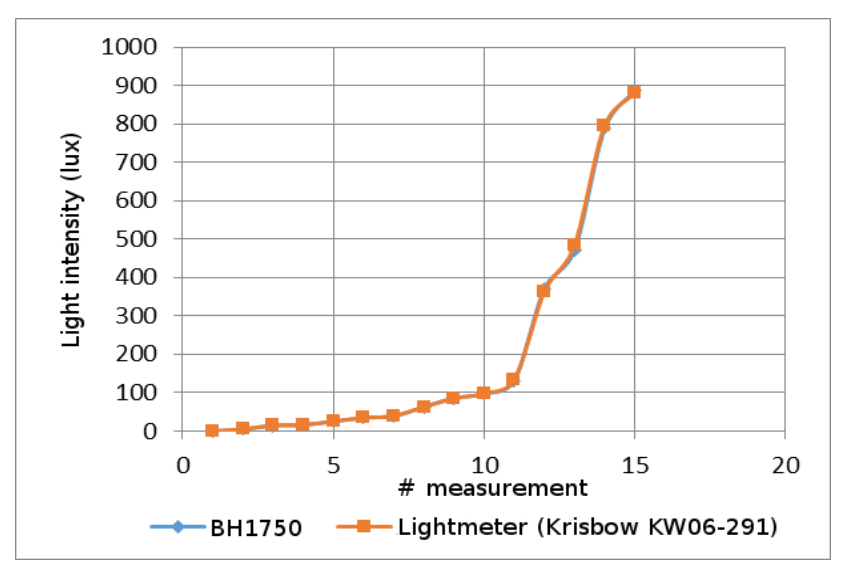

Figure 8. The Comparison Test Result of BH1750 Sensor and Light Meter

The test on the Sensor was conducted at 10 times of reading. The Sensor and the comparing measurer were place close by. Table 3 displays the test result from the Sensor and the comparing measurer towards the changes in the temperature and humidity.

Table 3. The Test Result of SHT11 Sensor

\begin{tabular}{|c|c|c|c|c|c|c|}
\hline \multirow{2}{*}{ No } & \multicolumn{2}{|c|}{ Sensor SHT11 } & \multicolumn{2}{c|}{ Comparator } & \multicolumn{2}{c|}{ Difference } \\
\cline { 2 - 7 } & Temp $\left({ }^{\circ} \mathrm{C}\right)$ & humidity $(\%)$ & Temp $\left({ }^{\circ} \mathrm{C}\right)$ & humidity $(\%)$ & Temp $\left({ }^{\circ} \mathrm{C}\right)$ & humidity $(\%)$ \\
\hline 1 & 29.52 & 66.69 & 29.7 & 67.1 & 0.18 & 0.41 \\
\hline 2 & 30.19 & 64.47 & 30.5 & 65.1 & 0.31 & 0.63 \\
\hline 3 & 30.48 & 62.52 & 30.6 & 64.4 & 0.12 & 1.88 \\
\hline 4 & 30.73 & 64.83 & 31.2 & 65.1 & 0.47 & 0.27 \\
\hline 5 & 30.98 & 64.50 & 31.4 & 65.5 & 0.42 & 1.00 \\
\hline 6 & 31.50 & 64.21 & 31.7 & 64.2 & 0.20 & 0.01 \\
\hline 7 & 32.15 & 57.60 & 32.2 & 56.2 & 0.05 & 1.40 \\
\hline 8 & 32.27 & 58.80 & 32.4 & 57.2 & 0.13 & 1.60 \\
\hline 9 & 32.84 & 59.82 & 32.9 & 59.6 & 0.06 & 0.22 \\
\hline 10 & 33.11 & 55.41 & 33.4 & 57.8 & 0.29 & 2.39 \\
\hline \multicolumn{7}{|c|}{ Average } \\
\hline
\end{tabular}




\section{Conclusion}

Based on the test result conducted to the application system equipped with the Sensor to monitor the environment quality on the wireless network; then, it can be concluded that:

1. This system is able to read a number of parameters as the control of the quality of the air environment surrounding such as nitrogen dioxide $\left(\mathrm{NO}_{2}\right)$, carbon monoxide $(\mathrm{CO})$, density of the dust particle, light intensity, temperature and humidity.

2. This system is equipped with RTC as the timer and GPS as the location coordinate in which the Sensor system in the wireless Sensor network is located as a node.

3. Sensor TGS 2600 is able to read the concentration of $\mathrm{CO}$ well with the range of the reading around from $0 \mathrm{ppm}$ to $100 \mathrm{ppm}$. The error reading for this Sensor is at 0.69 ppm.

4. Sensor GP2Y1010AUOF has a good measurement in reading the density of the dust particle from $0 \mu \mathrm{g} / \mathrm{m}^{3}$ to $500 \mu \mathrm{g} / \mathrm{m}^{3}$. Meanwhile, for the measurement above $500 \mu \mathrm{g} / \mathrm{m}^{3}$, the Sensor measurement would be adverse.

5. Sensor BH1750 is able to read the light intensity with the error in reading at 2.8 lux or 0,1 time higher than that of the measurer on the testing with the value of 0 lux until less than 900 lux.

6. Sensor SHT11 has a good measurement in reading the temperature and the relative humidity from the environment. The reading error based on the test for the temperature was at $0.22{ }^{\circ} \mathrm{C}$, and for the error in reading the relative humidity was at $0.98 \%$ from the measurer.

\section{Future Work}

The suggestion for the next research is that this system can be developed as a Sensor system to the portal of the information system on the environment with a wider area such as Semarang City.

\section{References}

[1] UI Green Metric: GreenMetric World University Rangking, http://greenmetric.ui.ac.id/ranking/detailUniv/2013/undip.ac.id. Accessed in 20 October 2014

[2] Nyoman Suwartha, Riri Fitri Sari, "Evaluating UI GreenMetric as a tool to support green universities development: assessment of the year 2011 ranking", Journal of Cleaner Production, Vol.61, (2013), pp. 46-53.

[3] T.S. Grindsted, "Sustainable universities - from declarations on sustainability in higher education to national law", Journal of Environmental Economics, Vol.2, Num. 2, (2011), pp.29-36.

[4] Grindsted and Hol, "Thematic development of declarations on sustainability in higher education", Journal of Environmental Economics, Vol.3, Num. 1, (2012), pp.32-40.

[5] Saadatian, O., K.B.Sopian, E.Salleh., "Adaptation of Sustainability Community Indicators for Malaysian Campuses as Small Cities", Sustainable Cities and Society, Vol.6, (2013), pp.40-50.

[6] R. Lukman, D. Kranjc, P. Glavic, "University ranking using research, educational and environmental indicators", Journal of Cleaner Production, Vol.18, (2010), pp. 619-628.

[7] Woolner, P., Hall, E., Higgins, S., McCaughey, C.,\& Wall, K., "A sound foundation: What we know about the impact of environments on learning and the implications for Building Schools for the Future", Oxford Review of Education, Vol.33, Num.1, (2007), pp.47-70.

[8] Maria Azucena Vicente-Molina, Ana Fernandez-Sainz, Julen Izagirre-Olaizola, "Environmental knowledge and other variables affecting pro-environmental behavior: comparison of university students from emerging and advanced countries", Journal of Cleaner Production, Vol.61, (2013), pp. 130-138.

[9] R.F. Sari, "Methodology and evaluation of green and sustainable campus indicators for World University ranking", Proceeding of the International Ranking Expert Group-6 (IREG-6), Taipei, (2012).

[10] Princeton Review: Guide to 332 Green Colleges, (2014).

[11] E. Hazelkom, "World-class Universities or World-class Systems? Rankings and Higher Education Policy Choices", UNESCO Forum on Rankings and Accountability in Higher Education, Paris, (2011).

[12] LPPM Undip: Research Master Plan (RIP) Undip 2012-2016, (2012).

[13] Lindsay Baker, Harvey Bernstein: The Impact of School Buildings on Student Health and Performance, (2012). 
[14] Mendell, M.J. \& Heath, G.A., "Do Indoor pollutants and Thermal Conditions in Schools Influence Student Performance? A Critical Review of the Literature", Indoor Air, Vol.15, Num.1, (2005), pp.2752.

[15] Tanner, C.K, "Effects of School Design on Student Outcomes", Journal of Educational Administration, Vol.47, Num.3, (2009).

[16] Yong Han Ahna, Annie R. Pearce, Yuhong Wang \& George Wang, "Drivers and barriers of sustainable design and construction: The perception of green building experience", International Journal of Sustainable Building Technology and Urban Development, Vol.4, Num.1, (2013).

[17] Jianli Pan, Jain, R, Paul, S, "Nine lessons learned from a green building tested: A networking and energy efficiency perspective", World Congress on Sustainable Technology, (2013).

[18] Q Weng: Advances in Environmental Remote Sensing: Sensors, Algorithms, and Applications, (2011).

[19] K. Calvert, JM Pearce, WE Mabee, "Toward Renewable Energy Geo-information Infrastructures: Applications of GIScience and Remote Sensing that Build Institutional Capacity", Renewable and Sustainable Energy Reviews, Vol.18, (2013), pp.416-429.

[20] Jianwen Ai, Yong Xue, "A Processing Framework of Grid Workflow for Remote Sensing Quantitative Retrieval", International Conference on Remote Sensing, Environment and Transportation Engineering (RSETE 2013), (2013).

[21] Michael Matthies, Carlo Giupponi, Bertram Ostendorf, "Environmental decision support systems: Current issues, methods and tools", Environmental Modelling \& Software, Vol.22, Num. 2, (2007), pp. $123-127$

[22] B.S. McIntosha, J.C. Ascough II, M. Twery, J. Chew, A. Elmahdi, D. Haase, J.J. Harou, D. Hepting, S. Cuddy, A.J. Jakeman, S. Chen, A. Kassahun, S. Lautenbach, K. Matthews, W. Merritt, N.W.T. Quinn, I. Rodriguez-Rodan, S. Sieber, M. Stavenga, A. Sulis, J. Ticehurst, M. Volk, M. Wrobel, H. van Delden, S. El-Sawah, A. Rizzoli, A. Voinov, "Environmental decision support systems (EDSS) development Challenges and best practices", Environmental Modelling \& Software, Vol.26, Num. 12, (2011), pp. 1389-1402.

[23] Alexey Voinov, Francois Bousquet, "Modelling with stakeholders", Environmental Modelling \& Software, Vol.25, Num. 11, (2010), pp.1268-1281.

[24] UNEP Report, "Early Warning Systems: A State of the Art Analysis and Future Directions", Division of Early Warning and Assessment (DEWA). United Nations Environment Programme (UNEP), Nairobi, (2012).

[25] Kelly FJ, Fuller GW, Walton HA, Fussell JC., "Monitoring Air Pollution: Use of Early Warning Systems for Public Health", Respilogy, Vol.17, Num. 1, January (2012), pp.7-19.

[26] Emily G.Snyder, T.H.Watkins, P.A.Salomon, E.D.Thoma, R.W.Williams, G.S.W.Hagler, D.Shelow, D.A.Hindin, J.V.kilaru, P.Preuss, "The Changing Paradigm of Air Pollution Monitoring", Environmental Science \& Technology, Vol.47, Num. 20, (2013), pp.11369-11377.

[27] Xufeng Ding, Gang Xiong, Bin Hu, Li Xie, Shengxian Zhou, "Environment monitoring and early warning system of facility agriculture based on heterogeneous wireless networks", IEEE International Conference on Service Operations and Logistics, and Informatics (SOLI 2013), 2013.

[28] Feretti D, Ceretti E,De Donno A, "Monitoring air pollution effects on children for supporting public health policy: the protocol of the prospective cohort MAPEC study", BMJ Open, (2014).

[29] Widianto, E.D., Priguna S.P, Budi S, Arena B.C.P, " Design of Digital Sound Generator to Enhance Agricultural Productivity ", The 1st Conference on Information Technology, Computer and Electrical Engineering (CITACEE), (2013).

[30] Ardiyanto, Lutfi., Implementation of the XBee -Based Wireless Sensor Networks Case Study Monitoring Temperature and Humidity, IJEIS, Vol.2, No.2, (2012).

\section{Authors}

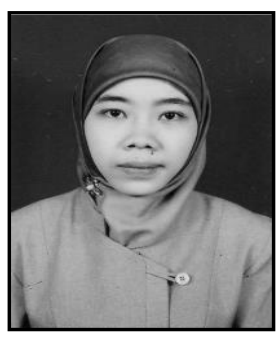

Oky Dwi Nurhayati, Born in Semarang, 2nd October 1979. Graduated from the Department of Telecommunication Engineering, Faculty of Engineering, Telecommunication Engineering Institute, Indonesia in 2002. Master from Post Graduate Program, Department Electrical Engineering, Gadjah Mada University, Indonesia in 2008 and got Ph.D in 2011 from Department of Electrical Engineering, Faculty of Engineering, Gadjah Mada University, Yogyakarta, Indonesia. From 2009- present she is a lecturer in the Department of Computer Engineering, Faculty of Engineering, Diponegoro University, Indonesia. Current and interest research is in biomedical image processing and software engineering. Oky Dwi Nurhayati is also a member of IAENG (International Association of Engineer, 

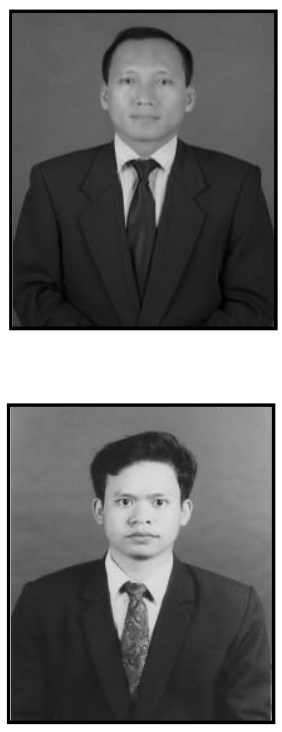

IMAVIS (International Journal on Image and Vision Computing), and IEEE.

Sumardi, Born in Sukoharjo, 11th November 1968. Graduated from Departement of Electrical Engineering, Diponegoro University Semarang, Indonesia in 1994. Master from Post Graduate Program, Instrumentation and Control, Institut Teknoogi Bandung, Indonesia in 1998. From 1994-present, he is a lecturer in Department of Elektrical Engineering, Faculty of Engineering, Diponegoro University, Indonesia. Current and interest research is in Control system and Instrumentotion.

Eko Didik Widianto, Born in Ponorogo, 26th May 1977. Graduated from Departement of Electrical Engineering, Institut Teknologi Bandung, Indonesia in 2001. Master from Post Graduate Program, Departement of Electrical Engineering, Institut Teknoogi Bandung, Indonesia in 2004. From 2010-present, he is a lecturer in Department of Computer Engineering, Faculty of Engineering, Diponegoro University, Indonesia. Current and interest research is in embedded system and programmable device. He is also a member of IEEE (the Institute of Electrical and Electronics Engineers). 